\title{
POTENTIAL FACTORS IN ENGAGING PHYSICAL ACTIVITY BEYOND PHYSICAL EDUCATION CLASS
}

\author{
Marino A. Garcia1, \\ Marlon T. Bojos', \\ Geraldine U. Sy ${ }^{3 \mathrm{i}}$ \\ 1,2Cebu Normal University, \\ Philippines \\ ${ }^{3}$ University of San Carlos, \\ Philippines
}

\begin{abstract}
:
The study determined the potential factors in the engagement of students' physical activity beyond regular physical education class. Participants were 476 secondary students aged between 16 and 22 from randomly selected public and private schools of Metro Cebu, Philippines. Cross-sectional survey design was used to examine the potential factors of students in engaging physical activity such as autonomy support, behavioural regulations, and intentions outside school. The study highlighted on the presence of physical learning resources or equipment as perceived by students as strong support in the continuous engagement in physical activity. Moreover, internal regulation is more accepted reason for students in allowing themselves to participate in any physical activity. Further, the intention of the students in partaking in physical activity is a form of leisure time for them. It is concluded that students and/or individuals will participate or engage in physical activity if they perceived supported and motivated. Additionally, it is recommended to provide and/or maintain high quality P.E. learning resources and fortify the engagement of students in physical activity in school through physical education subject to ensure higher transcendence at home and in the community.
\end{abstract}

Keywords: intentions, physical education, autonomy support, behavioural regulations

\section{Introduction}

One of the thrusts of Physical Education in the Philippines is to provide avenue for the students to participate in physical activity. Though, it has been proven that participation in physical education activities provide benefits in physical attributes or fitness of the students both in skill - related and health - related aspects (Biddle, Sallis, \& Cavill, 1998

i Correspondence: email garciam@cnu.edu.ph, bojosm@cnu.edu.ph, gusy@usc.edu.ph 
and Watts, Jones, Davis, \& Green, 2005) but recognizing the limitation, there are cases wherein physical inactivity has been reported throughout several countries (Armstrong, 1989; Dishman, 1994; Wang and Chia, Quek, \& Liu, 2006). Sallies and McKenzie (1991) elaborated that adult lifestyle is greatly influenced by positive experience in physical activity engagement which can promote wellness and public health while negative experiences triggered inactivity (Taylor, Blair, Cummings, Wun, and Malina, 1999). Thus, acquisition of physically active lifestyle mostly added to the adolescent stage is highly desired (Shephard and Trudeau, 2000 \& Ntoumanis, 2005). Therefore, one of the indicators in the success of the students' engagement in physical activity lies on the experiences in physical education in the junior level as the adolescence stage blossoms in this period particularly in both psychological and physiological aspects. Aptly, physical education teachers, as professionally trained, are highly capable of providing the needed motivation in increasing students' participation in physical activity.

The Self-determination Theory (SDT) provides approaches in indicating the potential factors in understanding students' participation in physical education (Deci \& Ryan, 1991, 2000). This theoretical approach has been successful in the perspective of education (Ryan \& Deci, 2006; Vallerand, Fortier, \& Guay, 1997) and in different sporting events (Hollembeak \& Amorose, 2005 and Thogersen-Ntoumani \& Ntoumanis, 2006). However, the use of this approach is limited in the context of physical education (Hagger, Chatzisarantis, Culverhouse, \& Biddle, 2003). The SDT approach explains the needs of an individual in different forms and satisfaction. People tend to be motivated if they find happiness or enjoyment out of their choices and capability to pursue the activity with the support of the people they cared for (Gagne, 2003). Additionally, the presence of accessible physical resources or equipment in engaging physical activity provides utmost support in physical activity endeavour (Garcia, Bojos, \& Canillas, 2018).

In Philippine education, reforms through Republic Act 10533 otherwise known as Enhanced Basic Education-K12 and CMO 46 Policy - Standard to Enhance Quality Assurance in the Philippine Higher Education through an Outcomes-Based and Typology-Based continue to strive in setting the policies standards and guidelines inclusive of Physical Education, which is responsible in contributing to producing productive graduates that could perform well in the work place and even at any given (personal) time. Moreover, in reiteration, one of the physical education's ultimate goals is active engagement of regular physical activities for a lifetime. In establishing a strong foundation, physical education as a course and discipline is offered in schools in multigrade levels as mandated by RA 5708, an Act of Providing for the Promotion and Financing of an Integrated Physical Education and Sports Development program for the schools in the Philippines and Article XIV, Section 19 of the Philippine Constitution which mandates that:

"The State shall promote physical education and encourage sports programs, league competitions, and amateur sports, including training for international competitions, to foster self-discipline, teamwork, and excellence for the development of a healthy and alert 
citizenry. All educational institutions shall undertake regular sports activities throughout the country in cooperation with athletic clubs and other sectors."

The foregoing statements strongly prove that regular school physical activity participation of the students' ages 5 to 17 years old is evident through the structured physical education classes. Hence, the study purposely looked into the physical education class experience and the potential factors particularly on students' perceived autonomy support, behavioural regulation and physical activity intentions outside of school or beyond physical education class. Further, the study was conducted to draw and identify areas for improvement and strong points of the physical education classes and subsequently propose for an improved delivery of the program for curriculum enrichment in junior Physical Education classes in line with $\mathrm{K}$ to 12 Basic Education Reform.

\section{Conceptual Framework}

Perceived Autonomy Support, Behavioural Regulation in PE and Physical Activity Intentions Framework

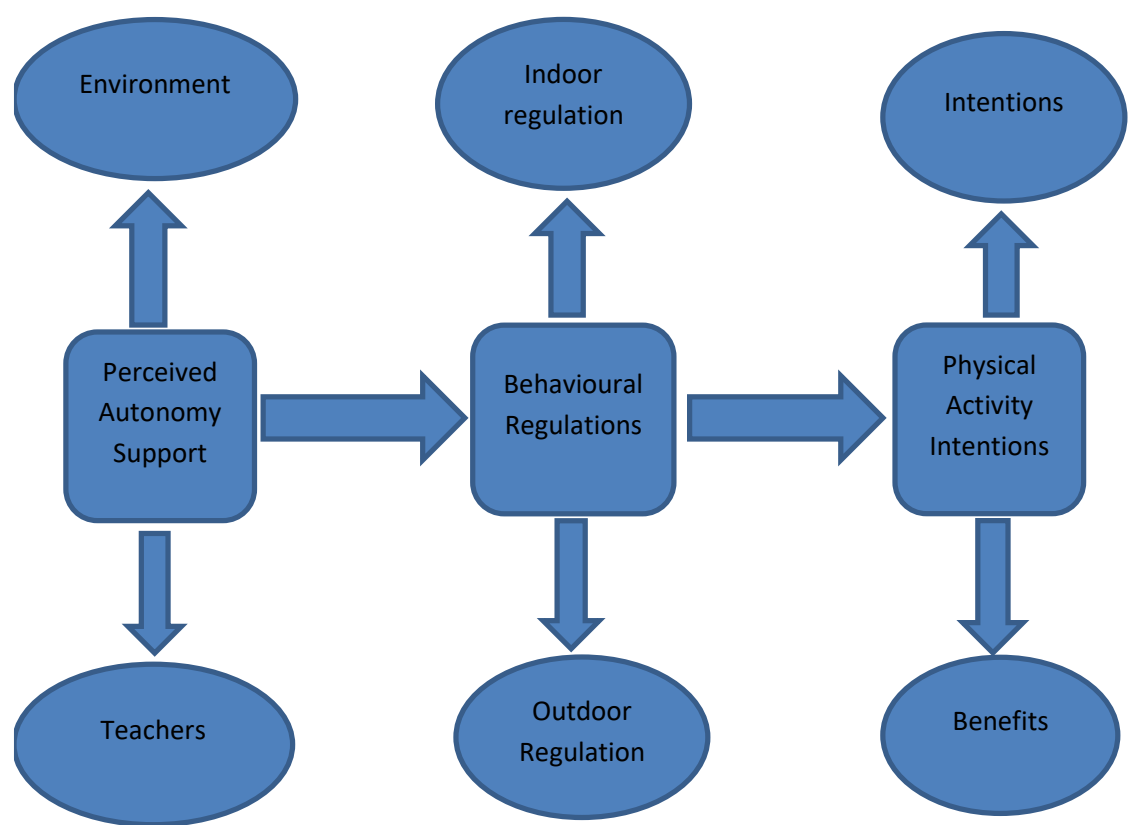

Figure 1: Potential Factors in Students Engagement in Physical Activity

The framework provides the different potential factors that can greatly influence the engagement of students in physical activity outside school or beyond physical education class. There are three identified factors such autonomy support (environment and teachers), behavioural regulations (indoor regulations and outdoor regulations) and physical activity intention (intentions and benefits) that can influence the student to decide to engage in physical activity beyond physical education class. 


\section{Materials and Methods}

\subsection{Design}

This study used a cross-sectional survey design in gathering, analyzing, interpreting the data to answer the research questions. This is believed appropriate as it looked into the classroom experiences of the students particularly on physical activities and teachers' approaches in teaching physical education. The data collection was conducted in Metro Cebu specifically Lapu Lapu City, Minglanilla Cebu, and Cebu City, Philippines. The study locales were selected considering the proximity and accessibility and more importantly, these sufficiently provide the necessary data for the study. This could be beneficial to the study locale particularly to the schools for their improvement in the implementation and revision of their physical education curriculum.

\subsection{Participants and Instruments}

Responses were obtained from 476 Grades 9 and 10 students of public and private coeducational schools of Metro Cebu. Clustering of schools for North, South and Cebu City was done. One intact class was randomly selected for grades 9 and 10. Purposely focusing on these grade levels in order to draw implications for curriculum enrichment in junior Physical Education classes in line with K to 12 Basic Education Reform.

This study utilized a survey questionnaire as a tool in gathering the data. The survey questionnaire has four parts, part A answers on the personal choice of physical activity done outside school using the Sport Climate Questionnaire (Brickell, Chatzisarantis, \& Pretty, 2006; Deci, 2001; Hagger et al., 2003), part B describes on the perceived autonomy support of students inside classroom physical education using Perceived Locus of Causality scale (Goudas, Biddle, \& Fox, 1994), part C shows the students' varied behavioral regulations towards physical activities in their physical education class (Hagger et al., 2003) and part D is the physical activity intention of students to do physical activity outside school (during leisure time) (Ajzen and Madden, 1986). These instruments were modified and changed slightly to suit the context of physical education.

\subsection{Ethical Considerations and Data Analysis}

Ethical considerations were secured prior to the conduct of the study. Moreover, standard protocol was adhered to in gathering the data by transmitting letters to the Department of Education, Regional Director's Office and School Principals for endorsement and approval. With the presence of the PE teachers, the research questionnaires were administered and retrieved by the researchers on the same day of every school respondent, and then proceeded with data analysis and interpretation.

Descriptive Statistics using means and standard deviations of students' responses were consistent or homogeneous while larger values indicate more dispersion or variability of the responses. Also, frequency counts and percentages were used to describe the data on the different variables of the study. The result was further summarized and presented in frequency and percentage distribution tables. 


\section{Results and Discussions}

This part presents, analyzes and interprets the results and discussions of the study.

Table 1: Perceived Autonomy Support in Physical Education

\begin{tabular}{|c|c|c|c|c|c|c|}
\hline \multirow{3}{*}{$\begin{array}{l}\text { Perceived } \\
\text { Autonomy } \\
\text { Support }\end{array}$} & \multicolumn{4}{|c|}{ Type of School } & \multirow{2}{*}{\multicolumn{2}{|c|}{ Total }} \\
\hline & \multicolumn{2}{|c|}{ Private } & \multicolumn{2}{|c|}{ Public } & & \\
\hline & No. & $\%$ & No. & $\%$ & No. & $\%$ \\
\hline Low & 6 & 3.0 & 27 & 9.7 & 33 & 6.9 \\
\hline Moderate & 66 & 33.3 & 131 & 47.1 & 197 & 41.4 \\
\hline High & 126 & 63.6 & 120 & 43.2 & 246 & 51.7 \\
\hline Total & 198 & 41.6 & 278 & 58.4 & 476 & 100.0 \\
\hline
\end{tabular}

Table 1 presents the perceived autonomy support of the grades 9 and 10 PE students in public and private schools at various levels (low, moderate, high). Between private and public schools, majority of the PE students in private schools have high perceived autonomy support while majority of public-school students have moderate (47.1\%) perceived autonomy support. This shows that more PE students in private schools have experienced stronger autonomy supported classroom environment compared to public school students due to the availability of learning resources. Studies conducted by Eime, R. M. et al. (2017), Higgerson, J. et al. (2018), Seu-jeng Huang, et al. (2016), proved that provision of sports and fitness facilities was positively associated with the increase in participation rate in the community. Thus, having sports facilities or adequate P.E. learning resources augment the motivation and/or intention of the students to engage in physical activity. Moreover, the difference between private and public schools' perceived autonomy support reflects the measure of impact (autonomy-supportive) by the PE teachers to the PE students.

Table 2: Behavioral Regulations of Students $(\mathrm{N}=476)$

\begin{tabular}{|l|c|c|c|c|}
\hline Behavioral Regulations & Mean & Std. Deviation & Lowest Value & Highest Value \\
\hline External Regulation & 3.068 & 1.3320 & 1.0 & 7.0 \\
\hline Interjected Regulation & 3.432 & 1.3075 & 1.0 & 7.0 \\
\hline Identified Regulation & 6.158 & 1.0195 & 1.0 & 7.0 \\
\hline Intrinsic Motivation & 6.139 & .9891 & 1.0 & 7.0 \\
\hline Relative Autonomy Index & 8.868 & 4.4851 & -8.7 & 18.0 \\
\hline
\end{tabular}

Table 2 reveals the types of behavioral regulations by the students in the PE class. In a scale of 1 to 7 with 1 as not at all true and 7 as very strongly true, the highest mean score 6.158 is attributed to identified regulation which implies that the students' motivation towards physical activity in the class is done because they find it beneficial and important. Thus, choosing to perform freely. Intrinsic motivation having a mean score of 6.139 tells that the students engaged in classroom physical activity for their own sake, that is, for the pleasure, fun and satisfaction derived from it, as well as the optimal challenge being experienced. Interjected regulation has a low mean value of 3.432, which 
speaks of the students' engagement in classroom physical activity due to avoidance of guilt and shame or to gain ego enhancements and feelings of worth. External regulation has the lowest mean score of 3.068, which means that students' engagement in classroom physical activity is due to external means such as rewards and constraints. The results support to the consistency of the SDT framework whereby intrinsic motivation and identified regulation to be normally high or positive and interjected regulation and external motivation to be normally low or negative which are predicted to the level of perceived autonomy support (Vallerand et al.,1992 \& Pelletier et al., 1995).

Table 3: Physical Activity Intentions of Students $(\mathrm{N}=476)$

\begin{tabular}{|l|c|c|c|c|}
\hline Physical Activity Intentions & Mean & Std. Deviation & Lowest Value & Highest Value \\
\hline PAI Students' Intention & 5.13 & 1.632 & 0 & 7 \\
\hline PAI Students' Plan & 5.25 & 1.576 & 0 & 7 \\
\hline
\end{tabular}

Table 3 presents the means and standard deviations of physical activity intentions among selected grades 9 and 10 PE students in private and public schools. The students' intention to be physically active in their leisure time (outside of school) was determined by adopting three items drawn from Hagger et al. (2003) and was based on the work of Ajzenand Madden (1986) then worded in a manner to correspond to behavioral criterion in time, context, target, and action (Ajzen \& Fishbein, 1980), participants responded to three questions. The students' intention to be physically active in their leisure time (outside of school) over a period of 2 weeks, for at least 30 minutes, and 3 days per week, is high with a mean score of 5.13 and a standard deviation of 1.632. On the other hand, the students' plan to be physically active in their leisure time (outside of school) over a period of 2 weeks, for a least 30 minutes, and 3 days per week with a mean of 5.25 and standard deviation of 1.576. Most of the students intend to be physically active in their leisure time (outside of school). The important step in facilitating students' active lifestyle outside school may begin in schools as it provides a structured learning that guarantees promotion of physical activity to many young people and potentially facilitate public health (Sallis et al., 1992).

Table 4: Distribution of Respondents' Intended Number of Days to Exercise Outside School

\begin{tabular}{|l|c|c|c|}
\hline No. of Days & Respondents & \% & Cumulative \% \\
\hline 0 & 37 & 7.8 & 7.8 \\
\hline 1 & 21 & 4.4 & 12.2 \\
\hline 2 & 134 & 28.2 & 40.3 \\
\hline 3 & 163 & 34.2 & 74.6 \\
\hline 4 & 63 & 13.2 & 88.0 \\
\hline 5 & 39 & 8.2 & 96.0 \\
\hline 6 & 10 & 2.1 & 98.1 \\
\hline 7 & 9 & 1.9 & 100.0 \\
\hline Total & 476 & 100 & \\
\hline
\end{tabular}


Table 4 presents the intended number of days to exercise outside of school (during leisure time) by adopting the third item drawn from Hagger et al. (2003), and was based on the work of Ajzenand Madden (1986) then worded in a manner to correspond to behavioral criterion in time, context, target, and action (Ajzen \& Fishbein, 1980). For example, "During my leisure time over the next 2 weeks, I intend to do active sports and/or vigorous physical activities for at least 30 minutes, a day per week". Furthermore, result shows that 3 days is the most preferred frequency of the students' intention to be physically active in their leisure time (outside of school) over a period of 2 weeks, for at least 30 minutes, which provides ample time for rest and recovery.

\section{Recommendations}

Further, it is recommended for the physical educators to begin improving their facilitating-learning skills in P.E. class as well as providing adequate learning resources class, to increase the interest and participation levels of the students toward physical activity. In the same vein, fortify the engagement of students to physical activity in school through physical education subject to ensure higher transcendence at home and in the community.

\section{Conclusion}

Participation in physical activity is significant in building good health and wellness. Thus, the study concluded that students and/or individuals would engage in physical activity if they perceived supported and motivated.

\section{Conflict of Interest}

The authors declare that there are no conflicts of interest.

\section{About the Authors}

Marino A. Garcia is an instructor and the Research Chair of College of Arts in Cebu Normal University College of Arts and Sciences, Cebu City, Philippines. He is a graduate of Bachelor in Secondary Education major in Physical Education, Health and Music. He is also a graduate of Master of Art in Teaching Human Kinetics in Southwestern University. Further, he is a candidate for Doctor of Philosophy in Education major in Research and Evaluation. His areas of research interest are on physical activity, exercise science, human movement, and physical education.

Marlon T. Bojos was a former Chairperson in the Department of Physical Education in the University of San Carlos and Cebu Normal University. Currently, he serves as a Senior Faculty in the College of Teacher Education of Cebu Normal University handling major courses of the Bachelor of Physical Education Program. His academic attainment includes Bachelor of Secondary Education specializing in Physical Education, Health and Music; Master of Arts in Education major in Physical Education, and currently working 
on a dissertation for the degree Doctor of Education major in Educational Management in Cebu Normal University. His research engagements revolve on exercise, health and physical education.

Geraldine U. Sy is a Senior High School Instructor and Coordinator in the area of Physical Education in the University of San Carlos. She is a Regional Trainer in Physical Education for private schools. She earned the Bachelor's Degree in Secondary Education major in Physical Education in the University of San Jose Recoletos, Master's Degree in Education major in Physical Education in Cebu Normal University, and currently working on academic requirements for the degree Doctor of Philosophy major in Research and Evaluation in Cebu Normal University. Her research engagements cover physical education in junior and senior high school.

\section{References}

Ajzen, I., \& Fishbein, M. (1980). Understanding attitudes and predicting social behavior. Englewood Cliffs, NJ: Prentice-Hall.

Ajzen, I., \& Madden, T. (1986). Prediction of goal-directed behavior: attitudes, intentions and perceived behavioral control. Journal of Experimental Social Psychology, 22, 453-474.

Armstrong, N. (1989). Children are fit but not active!. Education and Health, 7, 29-33.

Biddle, S. J. H., Sallis, J. F. and Cavill, N., Eds. (1998) Young and active? Young people and health-enhancing physical activity: Evidence and implications. Health Education Authority, London.

Brickell, T. A., Chatzisarantis, N. L. D., \& Pretty, G. M. (2006). Autonomy and control: augmenting the validity of the theory of planned behaviour in predicting exercise. Journal of Health Psychology, 11, 51-63.

Chatzisarantis, N. L. D., Hagger, M. S., Biddle, S. J. H., Smith, B., \& Wang, J. C. K. (2003). A meta-analysis of perceived locus of causality in exercise, sport, and physical education contexts. Journal of Sport and Exercise Psychology, 25, 284-306.

Deci, E. L., \& Ryan, R. M. (1991). A motivational approach to self: Integration in personality. In R. A Dienstbier (Ed.), Nebraska symposium on motivation: Perspective on motivation (Vol. 38, pp.237-288). Lincoln: University of Nebraska.

Deci, E. L., \& Ryan, R. M. (2000). The "what" and "why" of goal pursuits: Human needs and the self-determination of behavior. Psychological Inquiry, 11, 227-268.

Deci, E. L. (2001). The sport climate questionnaire. Retrieved March 11, 2006 from http://www.psych.rochester.edu/SDT/measures/auton sport.html.

Dishman, R. K. (1994). Advances in exercise adherence. Champaign, IL: Human Kinetics

Eime R. M., Harvey J., Charity M. J., Casey M., Westerbeek H., Payne W. R. The relationship of sport participation to provision of sports facilities and socioeconomic status: a geographical analysis. Aust N Z J Public Health. 2017 
Jun;41(3):248-255. doi: 10.1111/1753-6405.12647. Epub 2017 Jan 22. PMID: 28110514.

Gagne, M. (2003). The role of support and autonomy orientation in prosocial behavior engagement. Motivation and Emotion, 27, 199-223.

Garcia, M. A., Bojos, M. T., \& Canillas, J. A. (June, 2018). The emergent behavior in the engagement of physical activity in fitness centers. Journal of Physical Education Research, Volume 5, Issue II, 51-56.

Goudas, M., Biddle, S. J. H., \& Fox, K. R. (1994). Perceived locus of causality, goal orientations, and perceived competence in school physical education classes. British Journal of Educational Psychology, 64, 453-463.

Hagger, M. S., Chatzisarantis, N., Culverhouse, T., \& Biddle, S. J. H. (2003). The processes by which perceived autonomy support in physical education promotes leisuretime physical activity intentions and behaviour: a transcontextual model. Journal of Educational Psychology, 95, 784-795.

Higher Education Act of 1994, the virtue of the Commission en banc Resolution No. 1972011 dated August 8, 2011 Commission on Higher Education (CHED).

Higgerson, J. et al. (2018). Impact of free access to leisure facilities and community outreach on inequalities in physical activity: a quasi-experimental study. Retrieved on May 24, 2018 from http://jech.bmj.com/content/early/2018/01/12/jech2017-209882.

Hollembeak, J., \& Amorose, A. J. (2005). Perceived coaching behaviors and college athletes' intrinsic motivation: a test of self-determination theory. Journal of Applied Psychology, 17, 20-36.

Ntoumanis, N. (2005). A prospective study of participation in optional school physical education using a self-determination theory framework. Journal of Educational Psychology, 97, 444-453.

Pelletier, L. G., Fortier, M. S., Vallerand, R. J., \& Brie`re, N. M. (2001). Associations among perceived autonomy support, forms of self-regulation, and persistence: a prospective study. Motivation and Emotion, 25, 279-306.

Pelletier, L. G., Fortier, M. S., Vallerand, R. J., Tuson, K. M., Brie`re, N. M., \& Blais, M. R. (1995). Towards a new measure of intrinsic motivation, extrinsic motivation, and amotivation in sports: the sport motivation scale (SMS). Journal of Sport E Exercise Psychology, 17, 35-53.

Ryan, R. M., \& Deci, E. L. (2006). Self-regulation and the problem of human autonomy: does psychology need choice, self-determination, and will? Journal of Personality, 74, 1557-1586

Sallis, J. F., \& McKenzie, T. L. (1991). Physical education's role in public health. Research Quarterly for Exercise and Sport, 62, 124-137.

Sallis, J. F., Simons-Morton, B. G., Stone, E. J., Corbin, C. B., Epstein, L. H., Faucette, N., et al. (1992). Determinants of physical activity and interventions in youth. Medicine and Science in Sports and Exercise, 24, S248-S257.

Shephard, R., \& Trudeau, F. (2000). The legacy of physical education: influences on adult lifestyle. Pediatric Exercise Science, 12, 34-50. 
Sheu-jen Huang, et al. (2016). Policy, environment, and worksite fitness program participation among financial enterprise employees in Taiwan. Retrieved on May 15 , 2018

from https://www.sciencedirect.com/science/article/pii/S1728869X1630051X.

Taylor, W. C., Blair, S. N., Cummings, S. S., Wun, C. C., \& Malina, R. M. (1999). Childhood and adolescent physical activity patterns and adult physical activity. Medicine and Science in Sports and Exercise, 31, 118-123.

Thogersen-Ntoumani, C., \& Ntoumanis, N. (2006). The role of self-determined motivation in the understanding of exercise-related behaviours, cognitions and physical self-evaluations. Journal of Sports Sciences, 24, 393-404.

Vallerand, R. J., Fortier, M. S., \& Guay, F. (1997). Self-determination and persistence in a real-life setting: toward a motivational model of high school dropout. Journal of Personality and Social Psychology, 72, 1161-1176.

Vallerand, R. J., Pelletier, L. G., Blais, M. R., Brie` re, N. M., Senecal, C., \& Vallieres, E. F. (1992). On the assessment of intrinsic, extrinsic, and amotivation in education: evidence on the concurrent and construct validity of the academic motivation scale. Educational and Psychological Measurement, 53, 159-172.

Wang, C. K. J., Chia, M., Quek, J. J., \& Liu, W. C. (2006). Patterns of physical activity, sedentary behaviours and psychological determinants among Singaporean school children. International Journal of Sport \& Exercise Psychology, 4, 227-249.

Watts, K., Jones, T. W., Davis, E. A., \& Green, D. (2005). Exercise training in obese children and adolescents. Sports Medicine, 35, 375-392. 
Marino A. Garcia, Marlon T. Bojos, Geraldine U. Sy

POTENTIAL FACTORS IN ENGAGING PHYSICAL ACTIVITY BEYOND PHYSICAL EDUCATION CLASS

Creative Commons licensing terms

Authors will retain the copyright of their published articles agreeing that a Creative Commons Attribution 4.0 International License (CC BY 4.0) terms will be applied to their work. Under the terms of this license, no permission is required from the author(s) or publisher for members of the community to copy, distribute, transmit or adapt the article content, providing a proper, prominent and unambiguous attribution to the authors in a manner that makes clear that the materials are being reused under permission of a Creative Commons License. Views, opinions and conclusions expressed in this research article are views, opinions and conclusions of the author(s). Open Access Publishing Group and European Journal of Physical Education and Sport Science shall not be responsible or answerable for any loss, damage or liability caused in relation to/arising out of conflict of interests, copyright violations and inappropriate or inaccurate use of any kind content related or integrated on the research work. All the published works are meeting the Open Access Publishing requirements and can be freely accessed, shared, modified, distributed and used in educational, commercial and non-commercial purposes under a Creative Commons attribution 4.0 International License (CC BY 4.0). 